Studies in African Linguistics

Volume 46, Numbers 1\&2, 2017

\title{
A Corpus Study of Swahili Conditionals
}

\author{
Mohamed Mwamzandi \\ University of North Carolina, Chapel Hill
}

\begin{abstract}
In this paper I analyze Swahili conditional constructions via corpus analysis. Previous works on Swahili conditional markers categorize $k i$ as a high possibility marker and ikiwa as a low possibility marker. In this corpus based study, I show that Swahili conditional markers cannot be imbued with specific pragmatic implicatures. Further, I extend the analysis to include the relationship between the protasis and apodosis and how this relationship impacts the choice of Swahili conditional markers. Qualitative and quantitative analysis of the results indicate that both $k i$ and ikiwa may be used in conditionals with a high as well as neutral possibility of realization. However, the conditional conjunction ikiwa significantly differs from the $k i$ conditional morpheme in the analysis based on the relationship between the protasis and apodosis. While $k i$ is more frequently used in content and speech act conditionals, ikiwa is more frequently used in epistemic conditionals. The study is also extended to include the Swahili subjunctive morphemes $n g e$, used in conditionals with a low possibility of realization (hypotheticals) as well as counterfactuals, and ngeli/ngali, predominantly used in counterfactuals.
\end{abstract}

Keywords: conditional, Swahili, Bantu

\section{Introduction}

A few studies have discussed Swahili conditionals from a descriptive perspective. In some of these studies (Ashton 1944; Saloné 1983; Contini-Morava 2011), Swahili conditional markers are categorized using a four-level possibility scale: high possibility, neutral, low possibility and impossible, and the conditional markers are matched with a specific possibility level. The conclusions drawn in these studies are based on a few examples from Swahili literary texts and grammaticality judgments of constructed examples that assess the validity of the proposed analysis. While these studies attempt to link conditional markers with meanings related to level of possibility of the conditional markers under investigation, in this study, I show that the distribution of Swahili conditional markers on the possibility scale is not absolute.

This study explores, via corpus analysis, four Swahili conditional markers: two reality (indicative) conditional markers ( $k i$ and $i k i w a$ ) and two unreality (subjunctive) conditional markers (nge and ngeli/ngali). Statistical and contextual analysis of data extracted from the Helsinki Corpus of Swahili (HSC) shows that indicative conditional markers are used in conditionals whose possibility of fulfillment range from high possibility to low possibility. On the other hand, the subjunctive conditional markers are used in conditionals whose possibility of realization is low or impossible. Since the realization of the protasis may sometimes be based on truth value rather than possibility level (Dudman 1984; Wierzbicka 1997), I replace the terms high possibility, neutral, low possibility and impossible with van der Auwera's (1983) indeterminacy/contingency terminology: upper bound, neutral, lower bound, and impossible/false respectively. The category 'necessary/true' is missing because it was unattested in the dataset involving the four conditional 
markers under consideration (cf. Comrie 1986 on the use of if and other conjunctions such as since in English).

Further, this study also looks at categorization based on the relationship between the protasis and the apodosis where conditionals are categorized as content, epistemic, or speech act (Sweetser 1990; Dancygier \& Sweetser 2005). The study shows that the $k i$ conditional marker has the highest frequency in content and speech act conditionals while the ikiwa conditional marker has the highest frequency in epistemic conditionals. The subjunctive markers nge and ngeli/ngali are most frequently used in content conditionals and in a few instances, epistemic conditionals.

In this study, I used queries in the Helsinki Corpus of Swahili (HCS) to obtain concordance lists of the relevant conditional constructions. The HCS is an annotated corpus with a wide variety of written texts from various genres including literary texts, academic documents, religious texts, and news sites such as Nipashe and Uhuru. The diversity of the texts and the size of the corpus provide an excellent resource in the study of Swahili linguistic forms. However, the results of this study are limited to standard written Swahili because the HCS texts are from written sources. The application of the results to spoken standard Swahili and other Swahili varieties is left for future research.

The organization of the rest of the paper is as follows. In section 2, I briefly explain the methodology. Section 2.1 outlines the linear position of the protasis and the apodosis in the dataset. Section 2.2 explains conditional reality and possibility levels. Section 2.3 explains van der Auwera's (1983) terminology relating to the possibility scale, and the relevance of this scale in the analysis of indeterminate and contingent conditionals. Section 2.4 outlines the analysis of the Swahili conditionals in the dataset based on the relationship between the protasis and apodosis (Sweetser 1990; Dancygier and Sweetser 2005). Section 3 presents the results. Section 4 is the conclusion.

\section{Methodology}

There has been an increased emphasis on language studies whose results and generalizations are based on contextual analysis of linguistic forms. To this end, the primary source of data in this study is the Helsinki Corpus of Swahili (HCS) which has 14 annotated corpora with a total of 12.5 million words. In the HCS, concordance searches of the relevant data are done via inbuilt software, namely Lemmie. The corpora contain current Swahili newspaper articles, excerpts of literary texts, and educational and scientific material written in the mid to late $20^{\text {th }}$ century.

The dataset included 232 conditional constructions. Table 1 shows the number and the percentage of the conditional constructions analyzed for each of the four conditional markers.

Table 1: Number and percentage of conditional markers in the dataset

\begin{tabular}{|l|l|l|}
\hline Conditional Marker & Number & Percentage \\
\hline ki & 113 & 49 \\
\hline ikiwa & 55 & 24 \\
\hline nge & 39 & 16 \\
\hline ngeli/ngali & 25 & 11 \\
\hline Total & 232 & 100 \\
\hline
\end{tabular}

After extraction of the dataset from the HCS, the conditional constructions were tagged for a number of variables. These include: linear order of the protasis in relation to the apodosis (first, 
second); reality (indicative, subjunctive); possibility level (upper bound, neutral, lower bound, impossible/false); and the type of relationship between the protasis and the apodosis (content, speech act, epistemic). Each of these variables is explained in turn in sections 2.1 through 2.4.

2.1. Position of the Protasis. According to Greenberg's (1963: 84) universal 14, the unmarked word order in conditionals is that the protasis is sentence initial. In the dataset, the protasis mostly precedes the apodosis. Out of the 239 conditional constructions in the dataset, 194 had the protasis in initial position while 45 had the protasis in second position. This means that although the protasis is first in most of the examples presented in this paper, there are a few cases where the protasis is second. Due to the limitations in the scope of this study, the pragmatic implications of the linear position of the protasis and apodosis in Swahili conditionals is left for future research.

2.2. Reality and the possibility scale. In Swahili, the conditional markers $k i$ and ikiwa are considered indicative while nge and ngeli/ngali are considered subjunctive (Ashton 1944; Saloné 1983a, 1983b). According to Saloné (1983a), the subordinating conjunction ikiwa is used if there is a low probability that a condition will be fulfilled. while the verbal prefix $k i$ is used if there is a high probability that a condition will be fulfilled. The use of these conditional markers is illustrated using Saloné's (1983a: 313) examples in (1) and (2):

(1) [ikiwa mfalme a-ta-jiuzulu]P [w-ote wa-ta-furahi] Q If king 3SG-FUT-abdicate 3PL-all 3PL-FUT-happy

'If the king will abdicate, all of them will be happy.'

(2) $[$ Ni-ki-mw-ona $] P \quad[$ ni-ta-mw-ambia $] \mathrm{Q}$

1SG-CON-3SG-see 1SG-FUT-3SG-tell

'If I see him I will tell him.'

According to Saloné (1983a, 1983b), the use of ikiwa in (1) implies that there is a low likelihood for the fulfillment of the condition ikiwa mfalme atajiuzulu 'if the king will abdicate'. On the other hand, the use of the $k i$ conditional marker in (2) implies that there is a high likelihood for the condition nikimwona 'if I see him' to be fulfilled. In this paper, I explore the use of the indicative markers ikiwa and $k i$ and draw conclusions based on statistical and contextual analysis of examples from the HCS. I claim that both ki and ikiwa can be used in a protasis with a high possibility of realization as well as a protasis with a neutral possibility of realization.

On the use of the subjunctive conditional markers in Swahili, Ashton (1944) claims that nge is used if the realization of the condition is possible, while ngeli/ngali is an unreality conditional marker indicating that the realization of the condition is no longer possible. Some scholars have claimed that the distinction between nge and ngeli/ngali is no longer relevant and that the two subjunctive forms are in free variation (Loogman 1965; Jahadmy 1969; Zawawi 1971). Saloné (1983b) disagrees with the free variation analysis and claims that the use of ngeli/ngali indicates lower probability of the realization of the protasis, or counterfactuality, while the use of nge is unmarked; that is, a speaker uses nge to ignore the additional presuppositions associated with ngeli/ngali.

In this study, I claim that nge is used in conditionals with a low probability of realization as seen in (3) as well as conditionals with impossible/false protases as seen in (4). This claim is 
consistent with Saloné's (1983b) observation that nge is used in hypothetical conditionals as well as counterfactuals, but differs from the free variation analysis (Loogman 1965; Jahadmy 1969; Zawawi 1971).

(3) Tanzania ni nchi kubwa na yenye heshima katika eneo hili, Tanzania is 9 country 9 big and has respect in 5area 5this,

lakini [kama i-nge-zi-bana nchi zi-na-zo-i-shambulia Congo]P but if 9-CON-10-press 10countries 10-PRT-REL-9-attack 9Congo

[waasi wa-si-nge-kuwa na nguvu wa-li-zo-na-zo sasa]Q

rebels 3PL-NEG-CON-be with power 3PL-COP.REL-REL-have-10REF now

'Tanzania is a big country which is respected in this region, but if it would press the countries attacking Congo, the rebels would not have the power they have now.'

(4) [Ni-nge-jua $] \mathrm{P} \quad[$ ni-si-nge-kuja $] \mathrm{Q}$

1SG-CON-know 1SG-NEG-CON-come

'If I had known, I would not have come.'

Example (3) is a direct quotation of the then ambassador of the Democratic Republic of Congo in Tanzania by a journalist. The speaker presents a hypothetical situation in which Tanzania would put pressure of some sort, diplomatic or military, on the countries helping certain rebels attacking Congo. He goes on to predict that the rebels would not be as powerful as they were at the time if the condition specified in the protasis, Tanzania putting pressure on the rebels, were to be satisfied. Although Tanzania has not yet put any pressure on the countries attacking Congo at the time of speech, the fulfillment of the condition is remotely possible. Example (4) is produced by a person with some physical disabilities who had moved to a new place to take up a job as a public servant. The public servant in question is regretting having moved to the town because of the negativity and ridicule he has experienced due to his disability. The protasis, ningejua 'if I had known', is therefore counterfactual.

In the dataset, the subjunctive marker ngeli/ngali is almost always used in conditionals with impossible/false protases as seen in (5). Although it has been claimed that ngeli may also be used in hypothetical conditionals (Loogman 1965; Jahadmy 1969; Zawawi 1971; Saloné 1983a, 1983b), there was only one example of this in the corpus (example (16) discussed below).

\begin{tabular}{|c|c|c|c|c|}
\hline [Sasa & ni-ngeli-kuwa na & & mbaya]P & [si-ngeli-m-wek-e-a \\
\hline Now & 1SG-CON.PST-be with & intention & bad & NEG.1SG-CON.PST-3SG-put-APPL-FV \\
\hline
\end{tabular}

'If my intentions were bad, wouldn't I have poisoned him.'

In (5), the speaker is a lady who asserts, contrary to her husband's claim, that she had no bad intentions and did not plan, as alleged, to kill him. She reasons (in the apodosis) that she had the opportunity as a wife to poison the husband but did not do so. The subjunctive marker ngeli therefore marks the protasis as false due to the falsity of the apodosis. 
Notice that the speaker in (5) deductively reasons that the fulfillment of the protasis is false because of a reference to a past event that did not happen, that is, "I did NOT poison him". Thus a relevant distinction in assessing the level of realization of the protasis is that which exists between "indeterminate" (true/false) and "contingent" (necessary/impossible) conditionals (van der Auwera 1983, 1986) explained in section 2.3 .

2.3. Indeterminacy and Contingency. The degree of hypotheticality in indeterminate conditionals is based on truth value while the degree of hypotheticality in contingent conditionals is based on possibility. As explained earlier, Swahili studies have attempted to match the form of Swahili conditional markers with possibility levels: high possibility, neutral, low possibility and impossible. Following van der Auwera (1983), I use the terminology "upper bound", "neutral", "lower bound", and "impossible/false" in discussing the degree of hypotheticality. The valuation of the protasis using a joint contingent/indeterminate scale intuitively captures the idea that there are conditionals with a truth value based scale as well as conditionals with a possibility based scale. Furthermore, the indeterminate/contingent scale allows for a unified analysis of both the indicative and subjunctive conditionals.

To explain the difference between indeterminate and contingent conditionals, van der Auwera $(1983,1986)$ presents the conditional sentence in $(6)$ :

(6) If kangaroos have no tails, they topple over.

In the indeterminate reading it is either true or false that kangaroos have no tails. They topple over is a conclusion based on prior knowledge about the cause and effect relationship between the condition (of kangaroos having no tail) and the consequent (of toppling over). Dudman (1984, 1986) uses the term "hypothetical" for the indeterminate conditionals due to the deductive reasoning and hypothesis building from previous experience. In the contingency reading, it is possible but not necessary for kangaroos to have no tails, and if it is the case that a kangaroo has no tail, the kangaroo topples over. In other words, it is a contingent but not necessary feature for kangaroos not to have tails.

According to van der Auwera (1983), both indeterminacy and contingency can be gauged on a 3 point scale as shown in Table 2 .

Table 2: Indeterminacy/Contingency scale

\begin{tabular}{|l|l|}
\hline Level & Indeterminacy/Contingency \\
\hline 1 & Necessary/true \\
\hline $2 *$ & Upper bound \\
\hline 2 & Neutral \\
\hline $2 *$ & Lower bound \\
\hline 3 & Impossible/false \\
\hline
\end{tabular}

The "lowest degree of hypotheticality" involves conditionals with a scale value of 1 (necessary/true) while the "highest degree of hypotheticality" involves conditionals whose scale value is 3 (impossible/false) (Comrie 1986). According to van der Auwera (1983), within the contingent/indeterminate level 2, there are three sub-levels based on the semantics of the value 2 . At least 2 (upper bound, represented in the table as $2^{*}$ ) is a hybrid level between level 2 (neutral) 
and level 1 (necessary/true). At most 2 (lower bound, represented in the table as $2 *$ ) is a hybrid level between level 2 (neutral) and level 3 (impossible/false).

While previous Swahili studies on conditionals have focused on the possibility of the realization of the protasis, in this paper, I also look at how the apodosis may impact the choice of the conditional form used, as explained in section 2.4.

2.4. Classification based on the relation between the protasis and apodosis. There are three pragmatic possibilities in the interpretation of conditional constructions based on the relation between the protasis and the apodosis. These are content, epistemic and speech act (Sweetser 1990; Dancygier \& Sweetser 2005). I explain each of these pragmatic situations in turn.

Content conditionals express a causal relationship between the protasis and the apodosis. The protasis sets up the mental space within which the apodosis holds, that is, the content of the consequent is predicted based on the information provided by the protasis, as illustrated in (7):

(7) [Tu-ki-soma]P [tu-ta-erevu-k-a]Q

1PL-CON-read 1PL-FUT-clever-STV-FV

'If we get educated we will become wiser.'

In (7) there is a contingent relationship between the actual content of the protasis tukisoma 'if we get educated' and the content of the apodosis tutaerevuka 'we will become wiser'. The consequent of becoming wiser will happen if the people in question get educated.

Epistemic conditionals provide the mental space for some logical reasoning from a known effect to a cause or from a known cause to an effect. The protasis presents a premise that is the basis for the conclusion made in the apodosis.

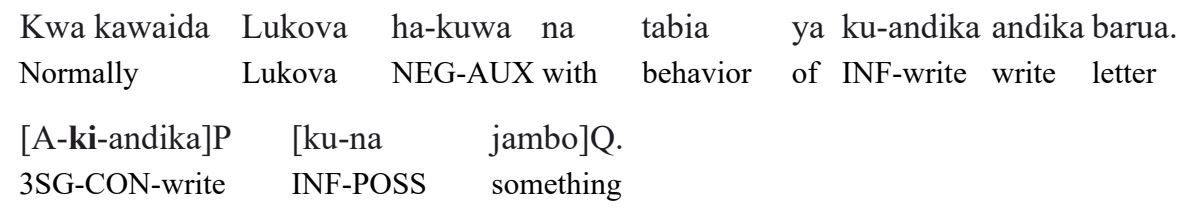

'Normally, Lukova would not write letters. If he (Lukova) writes (a letter), there is an issue.'

In (8), the speaker believes that for the condition (the writing of a letter by Lukova) to be realized, the apodosis (existence of an issue) must come first. While content conditionals have the temporal reference of the protasis sequentially following the apodosis, epistemic conditionals allow for the temporal reference of the apodosis to be before the protasis.

Speech act conditionals are conditional constructions whose apodosis, rather than making a statement, also perform a variety of illocutionary acts such warning, threatening, requesting, commanding, complaining, apologizing amongst others. In this study, this category also includes indirect speech acts exemplified by the question 'Can you reach the salt?', which could be interpreted as a request pass the salt (Searle 1975: 61). The propositional content of an indirect speech act has an illocutionary force that is not implicitly uttered but can be understood as a speech act due to shared background information and contextual clues. In speech act conditionals, the protasis functions as the comment for a speech act performed in the apodosis (Dancygier 1999; Van der Auwera 1986). A speech act conditional is illustrated in (9). 
(9) [U-ki-wa na deni]Q[lazima u-lip-e]P

2SG-CON-bewith debt must 2SG-pay-SBV

'If you have a debt, you must pay.'

In (9) the protasis, ukiwa na deni 'if you have a debt' constructs the mental space for the speech act performed in the apodosis, the command lazima ulipe 'you must pay'. In other words, the protasis is a sufficient condition for the performance of the speech act in the apodosis. I present the results of the study in section 3 .

\section{Results of the study}

In this section, I first explain the dataset under two general subdivisions based on reality: indicatives and subjunctives (section 3.1). In section 3.2 I discuss the effect of the indeterminacy/ contingency level on the choice of Swahili conditional expressions. Section 3.3 looks at how the relation between the protasis and the apodosis impacts on the conditional marker used in conditional constructions.

3.1. Categorization based on reality. Indicatives are conditionals with a protasis whose occurrence is envisaged as possible in reality. Of the 239 analyzed, there were 175 indicatives and 64 subjunctives. Out of the 175 indicatives, there were 120 conditionals with ki and 55 with ikiwa.

An interesting way to analyze types of conditional constructions used in certain contexts is to look at the nature of questions addressed by the protasis (Taylor 1997). It was notable that in most of the situations where ikiwa was used, the protasis was a condition-like conditional aimed at answering a polar question. The use of ikiwa as a condition answering a polar question is illustrated in (10).

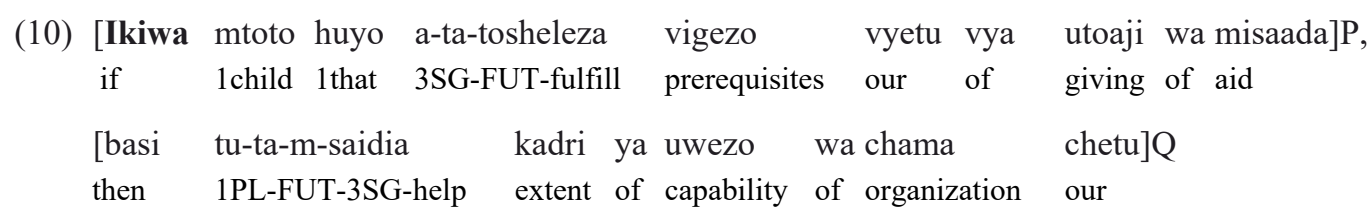

'If the child meets all the prerequisites we have set for giving financial aid, then we will help him to the best of our organization's ability.'

The answer to the polar question: Will your organization help the boy to pay his school fees, in (10) is 'yes', but on condition that the child fulfills the prerequisites set to be given financial aid. Thus, though not explicitly mentioned, the answer is 'no' if the child fails to fulfill the prerequisites. Most condition-like conditionals satisfy the criterion of "conditional perfection" which suggests that a condition of the form $\mathrm{X} \supset \mathrm{Y}$ invites the inference $\sim \mathrm{X} \supset \sim \mathrm{Y}$ illustrated by the celebrated example If you mow the lawn, I'll give you five dollars (Geis \& Zwicky 1971: 562). The implication is that if the intended hearer mows the lawn then the consequent is true, he will be given five dollars. Given society's understanding of agreements involving money, it is also understood that failure to mow the lawn will result in non-payment of the five dollars. 
On the other hand, conditionals with the marker ki tend to present situations with generic and temporal relationships. These conditionals seem to be giving responses to what and when questions as illustrated in (11) and (12) respectively.

(11)

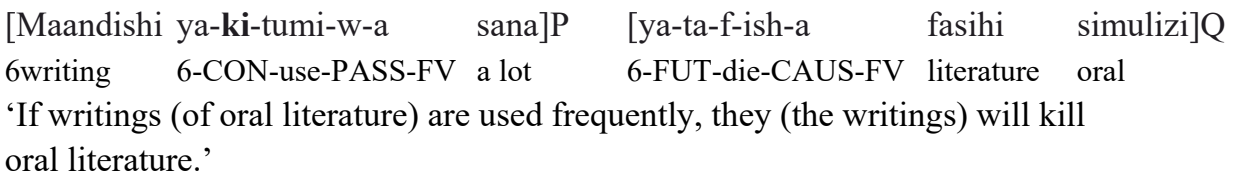

(12) [ng'ombe

$\begin{array}{lll}\text { a-ki-zaa ndama]P } & \text { [hu-m-lamba]Q } \\ \text { 1a-CON-give birth } & \text { 1a.calf } & \text { HAB-1a-lick }\end{array}$

1a.cow 1a-CON-give birth 1a.calf HAB-1a-lick

'When a cow gives birth to a calf, she licks it.'

Notice that (11) could be a response to the question: What circumstance will cause the death of oral literature? Example (12) could be a response to the question: When does a cow lick a calf?

Based on the indeterminacy/contingency level of the subjunctive conditional in question, the conditional constructions were labeled as "hypotheticals" or "counterfactuals" (Taylor 1997). The subjunctive marker nge was used in 39 conditionals: 14 hypotheticals and 25 counterfactuals $\mathrm{p}>0.05$. The insignificant frequency difference indicates that nge can be used both as a hypothetical marker as seen in (13) and a counterfactual marker as seen in (14).

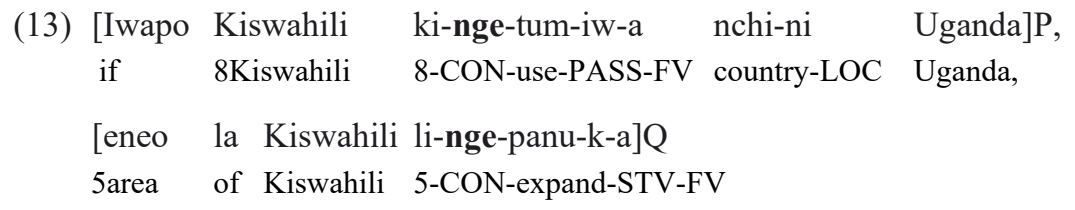

'If Kiswahili were used in Uganda, the area within which Swahili is spoken would expand.'

(14) [Kama ni-nge-kufa]P, [ni-nge-kufa kifo cha kijinga kabisa]Q if 1SG-CON-die, 1SG-CON-die death of stupid completely

'If I had died, I would have died a really stupid death.'

Example (13) with nge as the subjunctive marker is hypothetical because its fulfillment is remote but still possible. Though it was not the case at the time of speech that Kiswahili was being used in Uganda, it was possible that Kiswahili could be used there in future. Example (14) is produced by a character in a novel who had serious injuries inflicted by villagers in Tanzania who were against a government sponsored socialist program he was championing. In (14) nge is used as a subjunctive marker in a counterfactual conditional construction in which the speaker is referring to a past event where he was beaten up but did not die (cf. Saloné 1983b who claims that because of its application to both hypotheticals and counterfactuals, nge is unmarked for possibility level and counterfactuality).

Notice that the conjuction kama introduces the nge conditional marker in (14). In the dataset used in this study, kama was used 17/39 times in nge conditionals and 8/25 times in ngeli/ngali conditionals. There was no significant difference between nge hypothetical conditionals (9 constructions) and nge counterfactuals ( 8 constructions) introduced by kama $\mathrm{p}>0.05$. As I will 
explain below, ngeli/ngali conditionals with kama were mostly counterfactuals. It is however important to point out that an overt conjunction was used in all subjunctives when the protasis was second, as seen in (15).
(15) Ndugu Hilal a-li-sema pia kwamba [idadi ya watu wa-li-o-kufa Brother Hilal 3SG-PST-say also that count of people 3PL-PST-REL-die

'Brother Hilal also said that the number or people who died would have been larger if it were not for him requesting the passengers and his employees in the ship not to panic.'

The protasis in (15) is counter-to-fact because the speaker believes he requested the passengers and his employees in the ship not to panic hence a lower number of casualties. The conjunction used before the protasis is kama. I did not conduct grammaticality judgments to assess the unacceptability of examples such as (15) without a conjunction; but the presence of a conjunction in all second position protases points towards that direction. In general, kama is the most frequent conjunction in second position subjunctive protases (in the dataset kama was used 8/11 times in these contexts).

Of the 25 conditionals which used ngeli/ngali as the subjunctive marker, 24 were counterfactuals and only one conditional was a hypothetical. A counterfactual is illustrated in (16):

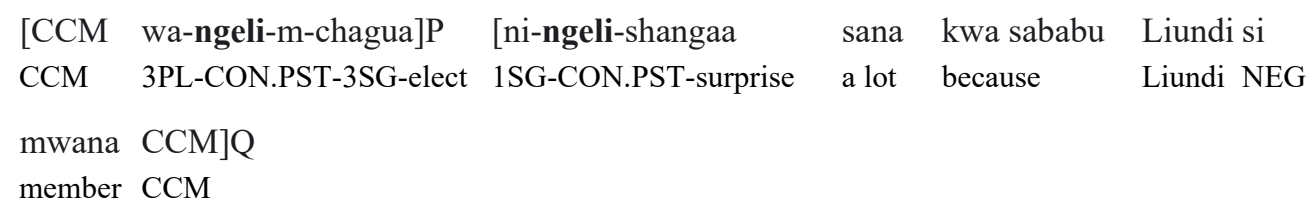

'If CCM members had elected him (Liundi), I would have been very surprised because Liundi is not a member of CCM.' (Chama cha Mapinduzi is a political party in Tanzania.)

Example (16) is counterfactual because Liundi was not elected by CCM to be the Tanzanian representative in the East African parliament.

The $n g e l i / n g a l i$ hypothetical condition is presented in (17). In (17) members of the public are lamenting about the security situation at a place where ferry services are provided.

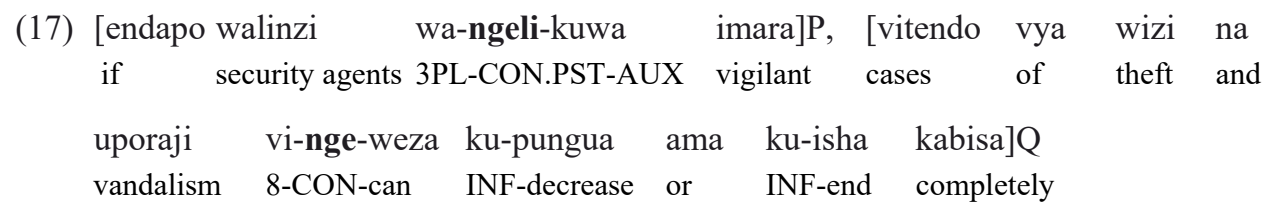

"If the security agents were to be vigilant, cases of theft and vandalism would reduce or completely end." 
The conditional marker ngeli in (17) can be interpreted as hypothetical because there is a possibility for the protasis (security agents being vigilant) to be realized in future. The frequency difference between the ngeli/ngali counterfactuals and hypotheticals is significant $\left(\mathrm{X}^{2}\right.$ $(1, \mathrm{~N}=25)=21.16, \mathrm{p}<0.001)$ indicating that ngeli/ngali is predominantly used as a counterfactual marker.

It is also important to note that although it is generally claimed by Swahili grammarians that ngeli and nge subjunctive markers in the protasis would require the same form in the apodosis, this is not always the case. In (17), for example, ngeli is used in the protasis while nge is used in the apodosis. There are a total of 7 conditional constructions with nge in the apodosis, including 5 ngeli/ngali subjunctives and $2 \mathrm{ki}$ indicatives. The example in (18) shows a conditional construction with $k i$ as the conditional marker having nge in the apodosis.

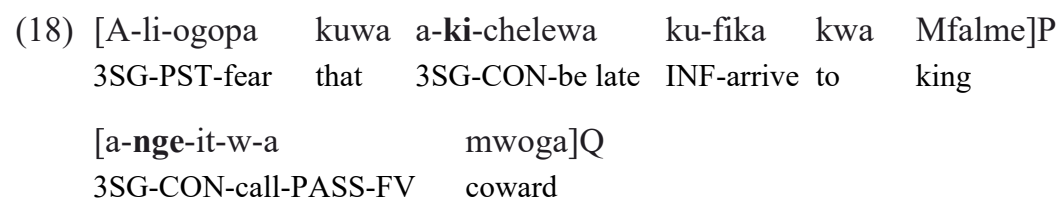

'He (Kisaka) was afraid that if he were to arrive late at the King's residence, he might be called a coward.

The conditional construction is indicative because Kisaka, the main protagonist in the story, was actually supposed to attend an elders' meeting at the king's residence to discuss matters of war. Kisaka had an important family issue to deal with before going to the meeting. He was afraid that the realization of the protasis, arriving late at the meeting, might be interpreted as cowardice. The use of $k i$ in the protasis rather than nge to match the subjunctive marker in the apodosis as expected is motivated by the pragmatic implicatures associated with the indicative marker $k i$ and subjunctive marker nge. Contextual analysis of the example reveals that the speaker in the source text believed that it was highly possible that he would be late for the meeting hence the use of $k i$ instead of nge which is used in the apodosis to mark the consequent 'being called a coward' as hypothetical. In the next section, I discuss the scalarity of the conditional markers used in the data set.

3.2. Indeterminacy/contingency scalarity. I mentioned earlier that there were four levels that were used in the indeterminacy/contingency scale, namely, upper bound, neutral, lower bound and impossible/false. Table 3 shows the conditional markers and their frequency for each of the indeterminacy/contingency levels.

Table 3: Indeterminacy/Contingency levels for each of the conditional markers

\begin{tabular}{|l|l|l|l|l|}
\hline $\begin{array}{l}\text { Conditional } \\
\text { marker }\end{array}$ & Upper bound & Neutral & Lower bound & Impossible/False \\
\hline ikiwa & 22 & 30 & 3 & 0 \\
\hline$k i$ & 53 & 56 & 4 & 0 \\
\hline ngeli/ngali & 0 & 0 & 1 & 24 \\
\hline nge & 0 & 0 & 14 & 25 \\
\hline Total & 75 & 86 & 22 & 49 \\
\hline
\end{tabular}


A total of 75 indicative conditionals were upper bound: $53 \mathrm{ki}$ and $22 \mathrm{ikiwa}$. Indicative conditionals with a neutral indeterminacy/contingency level were 86, 30 ikiwa and $56 \mathrm{ki}$. The frequency difference between upper bound and neutral conditionals for both the ki and ikiwa conditionals is insignificant $\mathrm{p}>0.05$.

Table 4 shows the column proportions of the indeterminacy/contingency scalarity.

Table 4: Indeterminacy/Contingency column proportional table

\begin{tabular}{|l|l|l|l|l|}
\hline $\begin{array}{l}\text { Conditional } \\
\text { marker }\end{array}$ & Upper bound & Neutral & Lower bound & Impossible/False \\
\hline ikiwa & 0.29 & 0.35 & 0.14 & 0.00 \\
\hline$k i$ & 0.71 & 0.65 & 0.18 & 0.00 \\
\hline ngeli/ngali & 0.00 & 0.00 & 0.05 & 0.49 \\
\hline nge & 0.00 & 0.00 & 0.64 & 0.51 \\
\hline
\end{tabular}

Table 4 shows that $k i$ is the most frequently used upper bound and neutral indicative, followed by ikiwa. No subjunctive has an upper bound or neutral indeterminacy/contingency level. I illustrate upper bound and neutral conditionals in (19) - (22).

Example (19) shows an upper bound conditional construction with $k i$ as the conditional marker.

(19) Huyu bwana i-na-elekea kazi yake ni ku-penda na ku-acha. Sasa [siku this man EXP-PRT-seem work his is INF-love and INF-leave. now day
a-ki-pata
kipusa kingine]P [a-ta-ku-acha
kama mwenzio]Q
3SG-CON-get lady another
3SG-FUT-2SG-leave
like your colleague

'This man seems to be in the business of loving and abandoning women. It follows that the day he gets another woman, he will abandon you like he has done to the other woman.'

The conditional construction in (19) was said by a judge advising a young lady who was taken to court because of a fight between her and another woman over a man. The judge was quite positive that the man will abandon the lady the moment he finds another beautiful woman.

As mentioned above, the dataset also indicates that the conditional conjunction ikiwa can be used in conditionals with an upper bound indeterminacy/contingency level as seen in (20).

$\begin{array}{llllll}\text { [Ikiwa } & \text { wadudu, ndege } & \text { na } & \text { wanyama ha-wa-f-i } & \text { kwa njaa]P } \\ \text { if } & \text { 2a.insects, 10birds } & \text { and } & \text { 2a.animals NEG-2-die-SBV } \\ \text { of } & \begin{array}{l}\text { hunger } \\ \text { [kwa nini }\end{array} & \text { wanadamu } & \text { wafe } & \text { kifo hicho]Q } & \\ \text { why } & \text { humans } & \text { 3PL-die } & \text { 7death 7that } & \end{array}$

'If insects, birds and animals do not die of hunger, why should human beings die such a death?'

The rhetorical question in (20) is a conclusion based on the upper bound indeterminate level of the protasis. The insignificant frequency between upper bound and neutral conditionals with ikiwa as the conditional marker indicates that ikiwa is not only used in conditionals with a low possibility 
of realization but also in conditionals with a high possibility of realization. This is contrary to Saloné's (1983a, 1983b) claim that ikiwa is used in conditional constructions with a low possibility of realization of the protasis.

The use of $k i$ in conditionals with neutral indeterminacy/contingency is illustrated in (21).

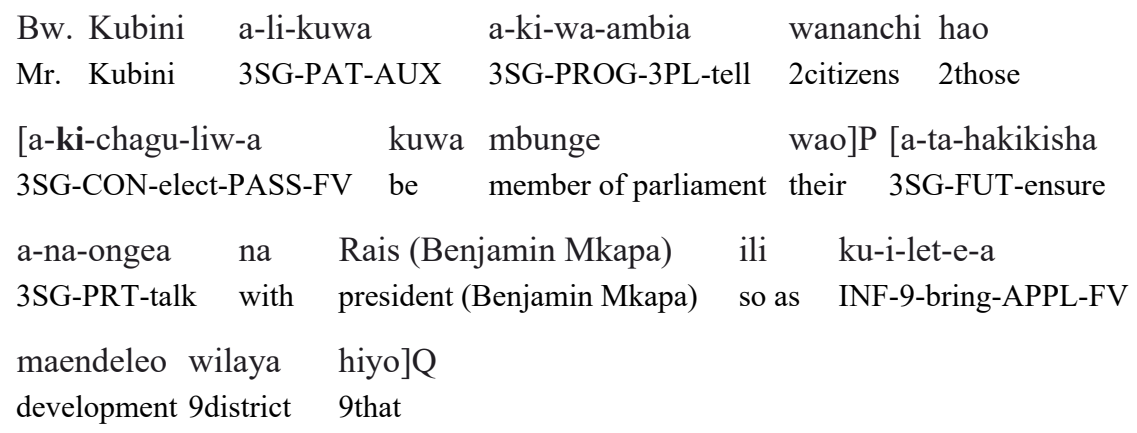

'Mr. Kubini was telling the voters that if elected as their member of parliament, he will make sure that he talks to the President (Benjamin Mkapa) so as to bring development in the district.'

In (21) a reporter quotes Mr. Kubini's promise to voters if they elect him. The protasis, if he gets elected, is neutral regarding the possibility of Mr. Kubini getting elected as the member of parliament of the district in question.

The use of ikiwa in conditionals with neutral indeterminacy/contingency is illustrated in (22).

(22) $[$ Polisi i-ta-m-kamata Bw. Mrema]Q,
9police 9-FUT-3SG-arrest Mr. Mrema,

'The police will arrest Mr. Mrema, if he conducts his political activities under the TLP political party in Temeke and Ubungo counties.'

In (22) the speaker warns that Mr. Mrema will be arrested if he conducts his political activities in Temeke and Ubungo but without committing himself that the condition will/will not be fulfilled.

There were a total of 25 conditionals with lower bound indeterminacy. Of these, 10 were indicatives ( $7 \mathrm{ki}$ and 3 ikiwa) and 15 were subjunctives (14 nge and 1 ngeli/ngali). Previous studies on Swahili conditionals have noted that nge/ngeli is used in subjunctives with high hypotheticality (Ashton 1944; Saloné 1983; Contini-Morava 2011). However, none of these studies on Swahili conditionals have explained the high hypotheticality of subjunctives in relation to the indicative markers with a low hypotheticality.

The conditional construction in (23) shows a lower bound indeterminate/contingent conditional with nge as the subjunctive marker. 
(23) [Mimi kama fedha i-nge-kuwe-po]P, [ni-si-nge-shind-w-a $1 \mathrm{SG}$ if 9money 9-CON-be-REL, 1SG-NEG-CON-win-PASS-FV INF-2SG-pay 'If I had money, I would not fail to pay you back.'

Example (23) is lower bound because the condition, though currently unfulfilled (the speaker has no money at the time of speech), has a slim possibility of being fulfilled. Table 4 (above) showing the column frequency proportions of the indeterminate/contingent levels indicates that $n g e$ is the most frequently used marker in conditionals with lower bound indeterminacy/contingency followed by ki, ikiwa, and ngeli/ngali in that order.

Table 5 with the row frequency proportions indicates that the ki, ikiwa and ngeli/ngali are least preferred in conditionals with lower bound indeterminacy/contingency.

Table 5: Row frequency proportions of indeterminacy/contingency levels

\begin{tabular}{|l|l|l|l|l|}
\hline Conditional marker & Upper bound & Neutral & Lower bound & Impossible/False \\
\hline ikiwa & 0.40 & 0.55 & 0.05 & 0.00 \\
\hline ki & 0.47 & 0.50 & 0.03 & 0.00 \\
\hline ngeli/ngali & 0.00 & 0.00 & 0.04 & 0.96 \\
\hline nge & 0.00 & 0.00 & 0.36 & 0.64 \\
\hline
\end{tabular}

In (24) I present a lower bound conditional construction with $k i$ as the conditional marker.

\begin{tabular}{|c|c|c|c|}
\hline $\begin{array}{ll}{[\text { Mtu }} & \text { wa pwani } \\
\text { person } & \text { of coast }\end{array}$ & $\begin{array}{l}\text { a-ki-zoea } \\
\text { 3SG-CON-get used }\end{array}$ & $\begin{array}{l}\text { chakula } \\
\text { food }\end{array}$ & $\begin{array}{l}\text { bila } \\
\text { without }\end{array}$ \\
\hline a-ta-zoea & chochote kile]Q & & \\
\hline 3SG-FUT-get used & anything else & & \\
\hline
\end{tabular}

'If a person from the (East African) coast gets used to food without coconut milk, he will get used to anything else.'

In (24) the speaker concludes that if a person from the East African coastal region gets used to food without coconut milk, then he can get used to anything. The conclusion in the apodosis is considered highly realizable if the protasis with high hypotheticality is realized.

Only the subjunctives have the impossible/false indeterminacy. There were a total of 49 subjunctive conditionals with impossible/false indeterminacy, 24 ngeli/ngali and 25 nge (see examples (14) and (16) for counterfactual subjunctives with nge and ngeli/ngali respectively).

In summary, the results show that, both $k i$ and ikiwa can be used in upper bound as well as neutral conditionals. In a few cases, ki and ikiwa may be used in lower bound conditionals. The subjunctive nge is used in lower bound and impossible/false conditionals. The subjunctive ngeli/ngali is predominantly used in conditionals with impossible/false indeterminacy.

3.3. Relation between the protasis and the apodosis. As explained earlier, based on the relation between the protasis and the apodosis, the conditionals in the dataset were categorized as content, epistemic or speech act. Table 6 presents the results. 
Table 6: Number of conditionals for each relational category

\begin{tabular}{|l|l|l|l|}
\hline $\begin{array}{l}\text { Conditional } \\
\text { marker }\end{array}$ & Content & Epistemic & Speech act \\
\hline$i k i w a$ & 29 & 20 & 6 \\
\hline$k i$ & 79 & 13 & 21 \\
\hline ngeli/ngali & 21 & 4 & 0 \\
\hline nge & 32 & 7 & 0 \\
\hline Total & 161 & 44 & 27 \\
\hline
\end{tabular}

Table 7 and Table 8 show the row and column frequency proportions of the three relation categories for each of the conditional markers. The relation row and column frequency proportions indicate that, first, content conditionals are the most frequently used conditional functions. Second, ikiwa is the most frequently used conditional marker in epistemic conditionals. Third, the indicative $k i$ is the most frequently used conditional marker in speech act conditionals. Fourth, speech act conditionals are unattested in subjunctive conditionals in the dataset.

Table 7: Relation row frequency proportions

\begin{tabular}{|l|l|l|l|}
\hline $\begin{array}{l}\text { Conditional } \\
\text { marker }\end{array}$ & Content & Epistemic & Speech act \\
\hline ikiwa & 0.53 & 0.36 & 0.11 \\
\hline ki & 0.70 & 0.16 & 0.19 \\
\hline ngeli/ngali & 0.84 & 0.16 & 0.00 \\
\hline nge & 0.82 & 0.18 & 0.00 \\
\hline
\end{tabular}

Table 8: Relation column frequency proportions

\begin{tabular}{|l|l|l|l|}
\hline $\begin{array}{l}\text { Conditional } \\
\text { marker }\end{array}$ & Content & Epistemic & Speech act \\
\hline ikiwa & 0.18 & 0.45 & 0.22 \\
\hline ki & 0.49 & 0.30 & 0.78 \\
\hline ngeli/ngali & 0.13 & 0.09 & 0.00 \\
\hline nge & 0.20 & 0.16 & 0.00 \\
\hline
\end{tabular}

An important observation in this analysis is the frequency of epistemic conditionals with the conditional marker as ikiwa in relation to epistemic conditionals with $k i$ as the conditional marker. The row relative frequencies show that clauses with ikiwa have a relatively high frequency of content conditionals. However, the frequency difference between the ikiwa content, 29, and epistemic, 20, conditionals is insignificant $(\mathrm{p}>0.05)$. A closer analysis of the relative frequencies across the columns shows that ikiwa is the preferred conditional marker for epistemic conditionals. The ikiwa conditional marker has the highest column proportion of epistemic conditionals (0.45) followed by the $k i$ conditionals (0.30). I present an epistemic conditional with ikiwa as the conditional marker in (25). 


\begin{tabular}{|c|c|c|c|c|c|}
\hline$(25)$ & [Ikiwa & serikali & hasara hiyo,]P & [i-ta-kuwa & i-me-tokana \\
\hline & if & 9government & 9-FUT-get 9loss 9that & 9-FUT-AUX & 9-PERF-cause by \\
\hline & uwezo & mdogo & menejimenti]Q & & \\
\hline & ability & small & management & & \\
\hline
\end{tabular}

'If the government will get that loss (mentioned previously), it (the loss) will be because of poor management skills of the management team.'

In (25), the speaker asserts that if the government gets a loss in the provision of the services in question, the only reasonable explanation for the loss is poor management.

Further, the speech act conditionals with $k i$ as the conditional marker as seen in (26) have the largest column proportion (0.78), followed by ikiwa (0.22).

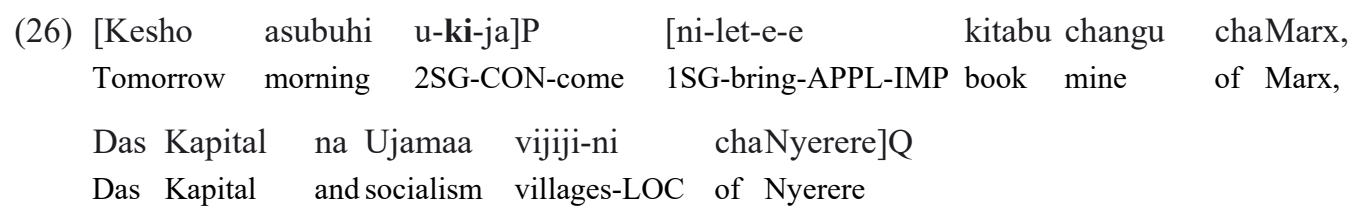

'Tomorrow morning if you come, bring me my book by (Carl) Marx, Das Kapital, and

Ujamaa vijijini 'Socialism in the Villages' by Nyerere.'

In (26), the protasis presents a situation which functions as the background information for the relevance of the speech act in the apodosis. The request niletee 'bring me' is only relevant if the hearer comes the next day.

In general, content conditionals are the most frequently used conditionals. However, epistemic and speech act conditionals are more likely to be used with indicative conditionals. Only a small proportion of subjunctive conditionals are used in epistemic and none are used in speech act conditionals. This is because it is more likely for conclusions and speech acts to be based on real situations rather than on hypothetical and counterfactual situations.

\section{Conclusion}

Previous studies on Swahili conditionals, whose analysis was mainly based on possibility scales, were helpful in understanding the pragmatics of Swahili indicative and subjunctive conditionals. However, the low number of examples and dependence on native speaker intuition affected the validity of the results. This study shows that $k i$ is the most frequently used conditional marker for conditionals with an upper bound contingency/indeterminacy. However, ki may also be used in conditionals with neutral contingency/indeterminacy. In fact, the frequency difference between upper bound and neutral conditionals with the marker $k i$ is insignificant $\mathrm{p}>0.05$. Further, contrary to Saloné's (1983) claim that the use of ikiwa indicates low possibility of realization, the frequency results indicate that ikiwa is mostly used when the possibility of the condition being fulfilled is upper bound (high possibility) or neutral rather than lower bound (low possibility).

Further, this study provides an alternative analysis based on the relation between the protasis and the apodosis hitherto unexplored in the study of Swahili conditionals. The results show that content conditionals are the most frequent in both the indicatives and the subjunctives. However, 
ikiwa is relatively more frequently used in epistemic conditionals than all the other conditional markers, while the $k i$ conditional marker is the most frequently used in speech act conditionals.

\section{Abbreviations Used}

$\begin{array}{llll}\text { 1SG/PL } & \text { First person singular/plural } & \text { INF } & \text { Infinitive } \\ 2 \mathrm{SG} / \mathrm{PL} & \text { Second person singular/plural } & \text { LOC } & \text { Locative } \\ 3 \mathrm{SG} / \text { PL } & \text { Third person singular/plural } & \text { NEG } & \text { Negative } \\ \text { AUX } & \text { Auxiliary } & \text { NUMBERS } & \begin{array}{l}\text { Noun classes and respective } \\ \text { subject/object agreement }\end{array} \\ \text { APPL } & \text { applicative } & & \text { Passive } \\ \text { CAUS } & \text { Causative } & \text { PASS } & \text { perfective } \\ \text { CON } & \text { Conditional } & \text { PERF } & \text { Possession } \\ \text { COP.REL } & \text { Copula relative } & \text { POSS } & \text { Present } \\ \text { EXP } & \text { expletive } & \text { PRT } & \text { Past } \\ \text { FUT } & \text { Future } & \text { PST } & \text { Relativizer } \\ \text { FV } & \text { Final vowel } & \text { REL } & \text { Subjunctive } \\ \text { HAB } & \text { Habitual } & \text { SBV } & \text { Stative } \\ \text { IMP } & \text { Imperative } & \text { STV } & \end{array}$

\section{References}

Ashton, Eric O. 1944. Swahili grammar (including intonation). London: Longmans \& Green.

Comrie, Bernard. 1986. Conditionals: A typology. In: Traugott, Elizabeth Closs, Alice Ter Meulen, Judy Snitzer Reilly \& Charles Ferguson (eds). On conditionals. New York: Cambridge University Press, 77-99.

Contini-Morava, Ellen. 2011. The message in the novel: (Ir)realis and negation in Swahili. Language Sciences 34(2): 200-215,

Dancygier, Barbara. 1999. Conditionals and predictions. Cambridge Studies in Linguistics (No. 87). Cambridge: Cambridge Studies in Linguistics.

Dudman, V. H. 1984. Conditional interpretations of if-sentences. Australian Journal of Linguistics 4(2): 143-204.

Dudman, V. H. 1986. Antecedents and consequents. Theoria 52: 168-199.

Geis, Michael L. \& Arnold M. Zwicky. 1971. On invited inferences. Linguistic Inquiry 2(4): 561-566.

Greenberg Joseph H. 1963. Universals of language. Cambridge, MA: MIT Press.

Jahadmy, Ali. 1969. Swahili made easy. Madison, WI: College Printing and Typing Company.

Loogman, Alfons. 1965. Swahili grammar and syntax. Pittsburgh, PA: Deliquesne University Press.

Saloné, Sukari. 1983a. The pragmatics of reality and unreality conditional sentences in Swahili. Journal of Pragmatics 7 (3): 311-324.

Saloné, Sukari. 1983b. Conditional Sentences in Swahili. PhD. Dissertation, UCLA. Distributed by ProQuest Dissertations \& Theses Global.

Searle, John R. 1975. Indirect speech acts. 1975. In: Cole, Peter \& Jerry Morgan (eds). Syntax and Semantics, vol. III. New York: Academic Press, 59-82. 
Taylor, John. 1997. Conditionals and polarity. In Athanasiadou, Angeliki \& René Dirven. On conditionals again. Amsterdam/Philadelphia: John Benjamins, 289-306.

van der Auwera, Johan. 1983. Conditionals and antecedent possibilities. Journal of Pragmatics 7(3): 297-309.

van der Auwera, Johan. 1986. Conditionals and speech acts. In: Traugott, Elizabeth Closs, Alice Ter Meulen, Judy Snitzer Reilly \& Charles Ferguson (eds). On conditionals. New York: Cambridge University Press, 197-214.

Wierzbicka, Anna. 1997. Conditionals and counterfactuals: Conceptual primitives and linguistic universals. In Athanasiadou, Angeliki \& Rene Dirven. On conditionals again.

Amsterdam/Philadelphia: John Benjamins, 15-53.

Zawawi, Sharifa. 1971. Kiswahili kwa kitendo. New York: Harper \& Row.

Mohamed Mwamzandi mymzandi@email.unc.edu
Submitted: 01 September 2015

Accepted: 14 March 2016

Revisions: 23 April 2016 